\title{
Increased neurogenesis after ACEA and levetiracetam treatment in mouse pilocarpine model of epilepsy
}

\author{
Mirosław Zagaja', Aleksandra Szewczyk', Agnieszka Haratym-Maj², Radosław Rola ${ }^{2,3}$, \\ Maciej Maj ${ }^{4}$, Jarogniew J. Łuszczki ${ }^{1,5}$, Marta Andres-Mach ${ }^{1}$ \\ ${ }^{1}$ Isobolographic Analysis Laboratory, Institute of Rural Health, Lublin, Poland \\ ${ }^{2}$ Department of Physiopathology, Institute of Rural Health, Lublin, Poland \\ ${ }^{3}$ Department of Neurological Surgery, Medical University, Lublin, Poland \\ ${ }^{4}$ Department of Biopharmacy, Medical University, Lublin, Poland \\ ${ }^{5}$ Department of Pathophysiology, Medical University, Lublin, Poland
}

Zagaja M, Szewczyk A, Haratym-Maj A, Rola R, Maj M, Łuszczki JJ, Andres-Mach M. Increased neurogenesis after ACEA and levetiracetam treatment in mouse pilocarpine model of epilepsy. J Pre-Clin Clin Res. 2017; 11(2): 136-141. doi: 10.26444/jpccr/81283

\section{Abstract}

Introduction and objectives. The aim of the study was to asses the impact of long-term therapy with the second generation antiepileptic drug levetiracetam (LEV) with arachidonyl-2'-chloroethylamide (ACEA), a highly selective cannabinoid CB1 receptor agoniston the process of neurogenesis in a mouse pilocarpine model of epilepsy (PILO). Additionally, a relationship was established between the treatment with ACEA in combination with LEV, and hippocampal neurogenesis in mouse PILO brain.

Materials and method. All experiments were performed on adolescent male CB57/BL mice injected i.p. with LEV (10 mg/kg), ACEA $(10 \mathrm{mg} / \mathrm{kg})$ and PMSF $(30 \mathrm{mg} / \mathrm{kg})$ (phenylmethylsulfonyl fluoride - a substance protecting ACEA against degradation by the fatty-acid amidohydrolase), pilocarpine (PILO, a single dose $290 \mathrm{mg} / \mathrm{kg}$ ) and methylscopolamine (30 min before PILO to stop the peripheral cholinergic effects of the pilocarpine, $1 \mathrm{mg} / \mathrm{kg}$ ). The process of neurogenesis was evaluated after 10 days treatment with LEV and ACEA.

Results. Obtained results indicated that the combinations of ACEA+PMSF+LEV and ACEA +PMSF increased the total number of total newborn cells compared to the control. Moreover, ACEA+PMSF administered alone and in combination with LEV had a significant impact on neurogenesis increasing the total number of newborn neurons compared to the control group. Neither LEV nor PMSF had a significant impact on the number of proliferating cells and newborn neurons when compared to the control PILO group. In turn, LEV administered alone decreased significantly the number of astrocytes. However, ACEA+PMSF has demonstrated significant increase of astrocytes compare to control mice.

Conclusions. These data provide substantial evidence that the combination of LEV+ACEA significantly increases the level of newborn neurons in the PILO dentate subgranular zone.

\section{Key words}

Levetiracetam, ACEA, neurogenesis, neurons, astrocytes, pilocarpine

\section{INTRODUCTION}

Levetiracetam (LEV), is one of the most common secondgeneration antiepileptic drugs, mainly used in the treatment of partial onset seizures with and without secondary generalization in adults and adolescents with newlydiagnosed epilepsy [1]. LEV is known to be ineffective in classic seizure models which screen potential compounds for antiseizure efficacy, such as maximal electroshock and pentylenetetrazol in rodents [2-5], whereas it has shown protective activity against acute seizures induced by $6 \mathrm{~Hz}$ electrical stimulation - a model of psychomotor seizures $[6,7]$. Additionally, its activity mechanism varies from that of other antiepileptic drugs and this may be related to a brain-specific stereo-selective binding site, synaptic vesicle protein $2 \mathrm{~A}$ (SV2A). SV2A appears to be important for the availability of calcium dependent neurotransmitter vesicles ready to release their content [8]. Numerous

Address for correspondence: Mirosław Zagaja, Isobolographic Analysis Laboratory, Institute of Rural Health, Jaczewskiego 2, 20-950 Lublin, Poland

E-mail: lasius1981@wp.pl

Received: 12 December 2017; accepted: 18 December 2017 studies have suggested that levetiracetam has considerable neuroprotective properties in both epileptic and nonepileptic disorders [9-13]. Its neuroprotection was demonstrated in several brain injury as well as neurodegenerative disease prototypes. These include brain damage resulting from status epilepticus (SE) or acute seizures, spontaneous epilepsy, closed head trauma, subarachnoid haemorrhage (SAH), hypoxic-ischemia, and stroke [14]. Nowadays, researchers are focused on the development of new potential anticonvulsants that also protect neurons against degeneration [15-18]. In searching for the best neurological drug protecting neuronal cells, stimulating neurogenesis, but also without developing side-effects, cannabinoids have proved to be a strong group of substances with many beneficial properties [19-25].

There is much evidence suggesting that both exogenous and endogenous cannabinoids can control cell genesis in the brain, although the effects can vary considerably depending on the cannabinoid, dose and duration of administration [26-28]. For example, chronic administration of the CB2 selective agonist HU-308 increased neural progenitor cell proliferation [28]. Similarly, chronic treatment with another synthetic cannabinoid - HU-210, a drug that has 
a high affinity for both $\mathrm{CB} 1$ and $\mathrm{CB} 2$ receptors, enhances proliferation and survival of cells in the rat dentate gyrus [29]. Interestingly, chronic administration of another synthetic CB1/CB2 agonist WIN55,212-2 administered to rats during adulthood was found to have no effect on the number of immature neurons in the dentate gyrus. However, interestingly, administration during adolescence decreased the number of immature neurons, an affect that is attributed to selective suppression of dorsal but not ventral hippocampal neurogenesis [30]. The endocannabinoid anandamide (AEA) or the CB1-specific agonist ACEA displayed a higher degree of neural stem cells neuronal differentiation and maturation in vitro, and enhanced neuronal stem cells differentiation into neurons, but not astrocytes and oligodendrocytes [31].

Previous results from neurogenesis research by the authors of the current study using ACEA and other LPP, valproate (VPA) in PILO mice, indicated that ACEA alone and in combination with VPA increased the total numbers of BrdUpositive cells, newly-born neurons and astrocytes, compared to the VPA group [32]. Taking into consideration all the above-mentioned information, the authors hypothesize that the combination of ACEA with LEV may have an impact on neurogenesis, as well as on LEV administered alone in PILO mice. To confirm this hypothesis, it was decided to evaluate the relationship between treatment with LEV+ACEA combination and hippocampal neurogenesis in a mouse PILO model of epilepsy.

\section{MATERIALS AND METHOD}

Animals and experimental conditions. All experiments were performed on adolescent male CB57/BL mice (6 weeks old). The mice were kept in colony cages with access to food and tap water ad libitum, under standardized housing conditions (natural light-dark cycle, temperature $20^{\circ} \mathrm{C}$ ). After 7 days of adaptation to laboratory conditions, the animals were randomly assigned to experimental groups consisting of 8 mice in each group. Each mouse was used only once. All tests were performed between 09:00-14:00. Procedures involving animals and their care were conducted in conformity with current European Community and Polish legislation on animal experimentation. Additionally, all efforts were made to minimize animal suffering and to use only the number of animals necessary to produce reliable scientific data. The experimental protocols and procedures listed below conformed also to the Guide for the Care and Use of Laboratory Animals and approved by the Local Ethics Committee at the Life Science University of Lublin, Poland (License No.: 23/2013).

Drugs. The following drugs were used in this project: levetiracetam (LEV; UCB Pharma, Braine-l'Alleud, Belgium), ACEA (arachidonyl-2'chloroethylamide; $\mathrm{N}$-(2-chloroethyl)-5Z,8Z, 11Z,14Z-eicosatetraenamide; pre-dissolved in anhydrous ethanol $(5 \mathrm{mg} / \mathrm{ml})$; Tocris Cookson Ltd., Bristol, UK), dissolved in distilled water and phenylmethylsulfonylfluoride (PMSF; ICN Biomedicals Inc., Irvine, CA, USA), used to limit the degradation of ACEA by inhibition of fatty acid amide hydrolase [33]. Pilocarpine (290 mg/kg) All drugs were injected intraperitoneally (i.p.) as a single injection, in a volume of $0.005 \mathrm{ml} / \mathrm{g}$.
Pilocarpine-induced convulsions. Mice were housed individually on a 12-hour day/night cycle at least 7 days prior to treatment with free access to food and tap water $a d$ libitum. Pilocarpine study was performed in accordance to the procedure described by Bahaskaran and Smith [34] with minor changes. Mice were administered an i.p. injection of methylscopolamine $(1 \mathrm{mg} / \mathrm{kg}) 30 \mathrm{~min}$ prior to injection of pilocarpine to reduce the peripheral cholinergic effects of the pilocarpine. Experimental animals were then injected i.p. with a single dose of pilocarpine $290 \mathrm{mg} / \mathrm{kg}$ [35]. Mice were carefully observed after pilocarpine injection to catch the first symptoms of convulsions. Seizure behaviour occurred about 2 hours after the pilocarpine injection and determined according to Racine's 1 - 5 scale $[36,37]$. The most important were convulsive seizures (categories 3 - 5) which correlate with the eventual development of spontaneous seizures and mossy fibre sprouting. A mouse that experienced a minimum of 3 generalized convulsive seizure events within 2 hours following pilocarpine injection was considered to have undergone status epilepticus (SE). The category 3-5 spontaneous seizures was assessed by passive observation $2 \mathrm{hr} /$ day, for one week after SE. Animals with spontaneous seizures (PILO mice) were used for the next step of the experiment. For animals where no seizures were observed, euthanasia was performed using carbon dioxide inhalation.

Drugs administration. Drug administration paradigm is similar as that described by Andres-Mach [32]. Animals were injected with ACEA and LEV for 10 days. Drug solutions were prepared ex tempore each day and administered once a day at the following doses: LEV-10 mg/kg, ACEA-10 mg/kg and PMSF-30 mg/kg. The doses of ACEA and PMSF were chosen based on previous publications [32, 38, 39] by the authors of the presented study. Animals were given BrdU (a marker of cell proliferation) as an additional injection for the last 5 days of treatment.

Tissue preparation. Three weeks after the last BrdU injection, the mice were anesthetized and perfused with ice-cold saline followed by freshly prepared, ice-cold $4 \%$ paraformaldehyde (PFA) in PBS. The brains were removed, post-fixed in fresh $4 \%$ PFA for $24 \mathrm{~h}$, and, subsequently, fiftymicrometer coronal sections were cut using a vibratome (VT1000S, Leica Biosystems, Wetzlar, Germany).

Immunohistochemical staining. Fifty-micrometer sections were stored at $4^{\circ} \mathrm{C}$ in cryoprotectant until needed. Freefloating sections were immunostained using primary antibodies and working concentrations: rat anti-BrdU (1:10; Oxford Biotechnology, Kidlington, Oxford, UK); mouse anti-NeuN (1:200; Chemicon, Temecula, CA, USA); goat anti-GFAP (1:100, Santa Cruz Biotechnology, Santa Cruz, CA, USA). Briefly, sections were rinsed with TRIS buffered saline (TBS), $\mathrm{pH} 7.4$, and then blocked for $30 \mathrm{~min}$ at room temperature with TBS containing $5 \%$ preimmune donkey serum and $0.3 \%$ Triton-X100 (TBS++). In the next step, sections were incubated for $24 \mathrm{~h}$ at $4{ }^{\circ} \mathrm{C}$ with primary antiNeuN and anty-GFAP antibodies diluted in TBS++ and then washed extensively with TBS buffer at room temperature. Subsequently, sections were incubated overnight at $4^{\circ} \mathrm{C}$ with secondary fluorochrome-conjugated antibodies in $\mathrm{TBS}++$, and again washed extensively at room temperature. For the 
BrdU identification, stained sections were post-fixed for $15 \mathrm{~min}$ at room temperature in $4 \%$ paraformaldehyde, rinsed twice with normal saline, and pretreated with $1 \mathrm{M} \mathrm{HCL}$ for $30 \mathrm{~min}$ at $37^{\circ} \mathrm{C}$. Next, sections were neutralized by rinsing twice with TBS and then blocked with TBS++. Blocked sections were incubated overnight at $4{ }^{\circ} \mathrm{C}$ with primary anti-BrdU antibody, washed extensively with TBS at room temperature, and incubated overnight at $4{ }^{\circ} \mathrm{C}$ with secondary fluorochrome-conjugated antibody in TBS++. Finally, stained sections were washed in TBS, incubated for 10 min in TBS containing DAPI, mounted and coverslipped.

Confocal microscopy and cell counting. Confocal imaging and quantitative analysis of newborn-cells was performed according to the method described previously $[33,38]$. To calculate the number of BrdU-positive (BrdU+) cells in the SGZ, at least 12 sections of a one-in-six series were scored per animal. All counts were limited to the dentate granule cell layer and a $50-\mu \mathrm{m}$ border along the hilar margin that includes the SGZ. The total number of BrdU+ cells displaying neuron-specific (NeuN) or astrocyte-specific (GFAP) markers was determined using confocal microscopy to score the colocalization of BrdU and phenotypic indicators in representative sections from each animal. Confocal microscopy and cell counting were performed using a Zeiss LSM 5 Pascal microscope and ImageJ software. Appropriate gain and black-level settings were obtained on control tissues stained with secondary antibodies alone. Upper and lower thresholds were always set using a range indicator function to minimize data loss due to saturation. Each cell was manually examined in its full $\mathrm{Z}$ dimension using split panel analysis, and only those cells for which the BrdU-positive nucleus was unambiguously associated with the lineage-specific marker, were scored as positive. For each lineage-specific marker, the percentage of BrdU-positive cells expressing the marker was determined [40]. The total numbers of lineagespecific BrdU-positive cells were calculated by multiplying this percentage by the total number of BrdU-positive cells in the dentate gyrus. The total numbers of respective cell types were obtained by multiplying the measured value by 6 ; overestimation was corrected using the Abercrombie method for nuclei with empirically determined average diameter of $13 \mu \mathrm{m}$ within a $50-\mu \mathrm{m}$ section [41].

Statistical analysis. For each endpoint, values for all animals from a given treatment group were averaged and standard errors of mean (S.E.M.) were calculated. The results were analyzed using one-way Analysis of Variance (ANOVA) followed by the Dunnet's test for multiple comparisons. All statistical tests were performed using commercially available GraphPad Prism version 5.0 for Windows (GraphPad Software, San Diego, CA, USA).

\section{RESULTS}

Impact of ACEA and LEV on total newborn cells in the dentate subgranular zone of PILO mice. Results from the neurogenesis study indicated that the combination of $\mathrm{ACEA}+\mathrm{PMSF}+\mathrm{LEV}$ PILO as well as ACEA+PMSF PILO increased the total number of BrdU positive cells in comparison to the control PILO group (Fig. 1). As mentioned

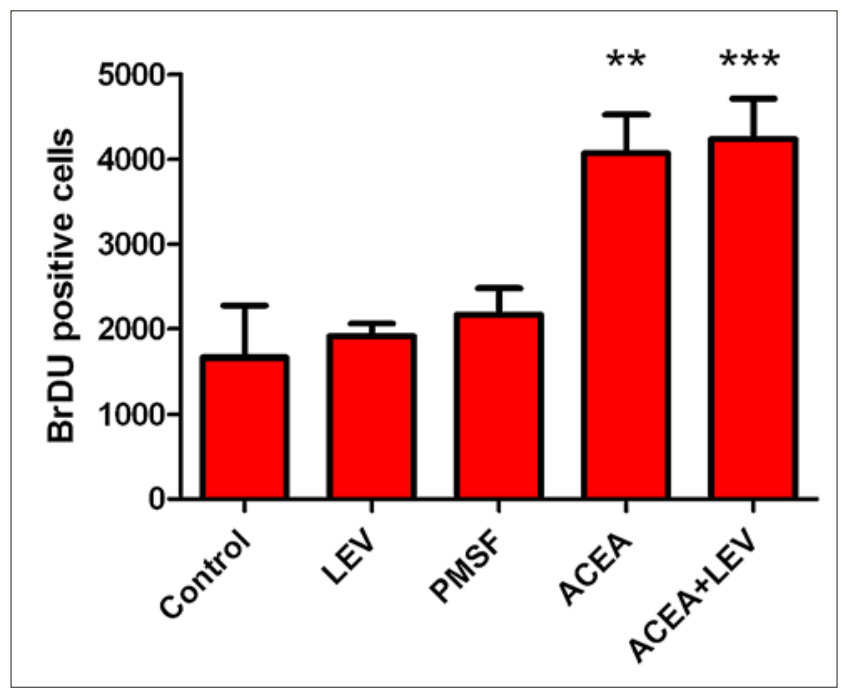

Figure 1. Effects of ACEA and LEV on newly-born cells in the dentate subgranular zone of PILO mice. The numbers of cells represent an estimate of the total number of positively labeled cells in the subgranular zone in both hemispheres. Results were analyzed using one-way analysis of variance (ANOVA) followed by Dunnet's test for multiple comparisons

${ }^{* *} p<0.01 ; * * * p<0.001$. Each bar represents the mean for 5 mice; error bars are S.E.M.

above, in the control PILO group, the total number of BrdU positive cells in the dentate gyrus of mice averaged $1,766 \pm 150$, while in ACEA +PMSF+LEV PILO mice, the average value was $4,237 \pm 479\left(\mathrm{~F}_{4,23}=13,41 ; \mathrm{n}=5 ; \mathrm{p}<0.001\right)$ (Fig. 1$)$, and ACEA + PMSF PILO mice the average value was $4068 \pm 457(\mathrm{p}<0.01$ for comparisons). No statistical significance was observed when comparing LEV PILO and PMSF PILO groups to the control PILO group ( $\mathrm{p}>0.05$ for comparisons).

Impact of ACEA and LEV on newborn neurons in the dentate subgranular zone of PILO mice. In the control PILO group, the number of BrdU positive cells colocalised with NeuN in the dentate gyrus of mice averaged $876 \pm 74$ while, ACEA+PMSF PILO-treated mice averaged 2246 \pm 253 and ACEA+PMSF+LEV PILO-treated mice averaged 2542 \pm 287 ; the difference was statistically significant $\left(\mathrm{F}_{4,23}=16.42\right.$; $\mathrm{n}=5 ; \mathrm{p}<0.001$ for comparison) (Fig. 2). The total number of NeuN/BrdU positive cells in PMSF PILO and LEV PILO mice showed no significant difference compared to control PILO group ( $\mathrm{p}>0.05$ for comparisons).

Impact of ACEA and LEV on newborn astrocytes in the dentate subgranular zone of PILO mice. ACEA+PMSF PILO groups revealed a significant impact on newborn astrocytes (Fig. 3), compared to the control PILO mice. The average number of astrocytes for control PILO mice was $118 \pm 10$, whereas for ACEA+PMSF PILO-treated mice it was $195 \pm 22$ $\left(\mathrm{F}_{4,23}=15.49 ; \mathrm{p}<0.01 ; \mathrm{n}=5\right.$; Fig. 3). Both ACEA+PMSF+LEV PILO (102 \pm 12$)$ and LEV PILO (65 \pm 5$)$ mice showed a reduction of GFAP positive cells when compare to the control PILO group; however only the difference for LEV PILO group was statistically significant ( $\mathrm{p}<0.05$ for comparisons). The total number of GFAP positive cells in PMSF PILO mice showed no significant difference compared to control PILO group ( $\mathrm{p}>0.05$ for comparisons). 


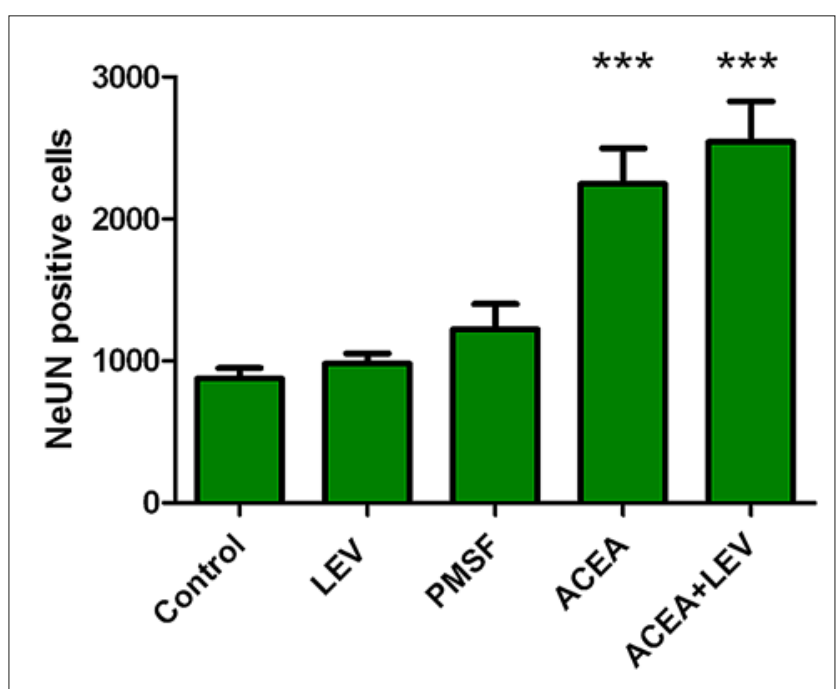

Figure 2. Effects of ACEA and LEV on newly-born neurons in the dentate subgranula zone of PILO mice. The numbers of cells represent an estimate of the total number of positively labeled cells in the subgranular zone in both hemispheres. Results were analyzed using one-way analysis of variance (ANOVA) followed by the Dunnet's test for multiple comparisons

${ }^{* * *} p<0.001$. Each bar represents the mean for 5 mice; error bars are S.E.M.

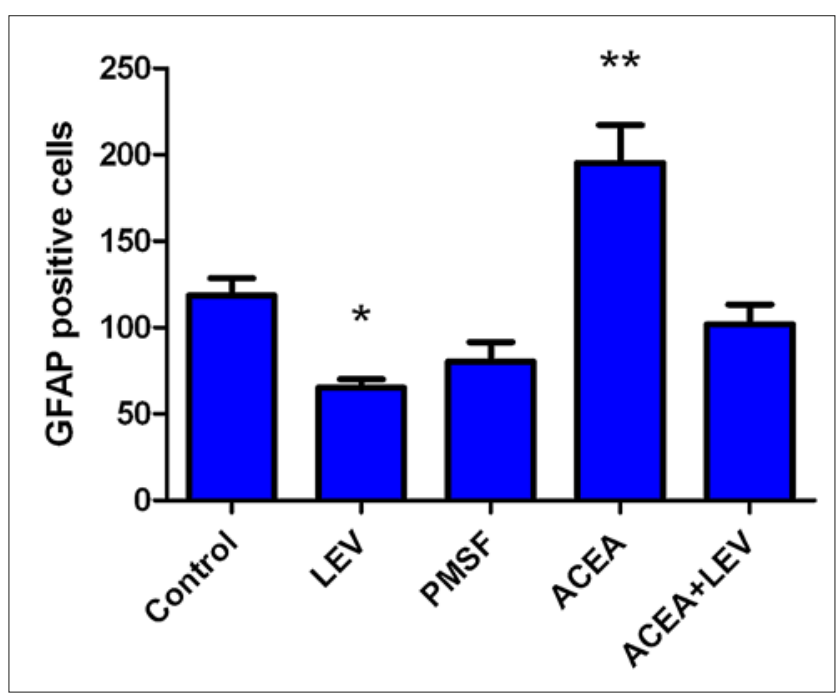

Figure 3. Effects of ACEA and LEV on newly-born astrocytes in the dentate subgranular zone of PILO mice. The numbers of cells represent an estimate of the total number of positively labeled cells in the subgranular zone in both hemispheres. Results were analyzed using one-way analysis of variance (ANOVA) followed by the Dunnet's test for multiple comparisons

${ }^{*} p<0.05 ;{ }^{* *} p<0.01$. Each bar represents the mean for 5 mice; error bars are S.E.M.

\section{DISCUSSION}

Obtained results indicated that ACEA PILO (10 mg/kg, i.p.) co-administered with PMSF (30 mg/kg, i.p.) significantly increased the total amount of BrdU positive cells. Similarly, the combination of ACEA+PMSF+LEV PILO also enhanced BrDU+cells. Moreover, a significant increase in NeuN+cells for ACEA+PMSF+PILO and ACEA+PMSF+LEV PILO compared to the control PILO-mice, which confirms enhanced neurogenesis. Neither LEV+PILO nor PMSF+PILO administered alone for 10 days had a significant impact on the number of proliferating cells when compared to the control PILO group.
LEV as a second-generation anti-epileptic drug (AED), is mainly approved for clinical use as monotherapy and may also be used for adjunctive treatment of patients with seizures [42]. LEV was found to act through the inhibition of the synaptic vesicle protein 2A [43], but also the inhibition of HVA-Ca ${ }^{2+}$ channels (N-type). Moreover, it can negate the inhibition of negative allosteric modulators, such as zinc and $\beta$-carbolines of $\gamma$ - aminobutyric acid (GABA)- and glycine-gated currents, and diminish the calcium release from intraneuronal stores $[43,44]$.

Additionally, results from different experimental research suggests that LEV provides antihyperalgesic effects in inflammatory pain [45-47], chronic pain [48] and neuropathic pain [49-51] models. Several studies have proposed that LEV possesses considerable neuroprotective properties in both epileptic and non-epileptic disorders [42]. Lee et al., [52] indicated that LEV treatment may effectively reduce status epilepticus-induced neuronal death in CA1 pyramidal cells, compared with diazepam treatment in rats. LEV as an add-on drug with diazepam could not alleviate status epilepticus-induced neuronal damage, compared with LEV alone.

Research using hypoxic ischemic brain injury induced by carotid artery ligation in rat pups showed that the numbers of positive apoptotic cells decreased significantly in the LEVtreated group compared with the saline group, which may be related with not only anti-epileptogenic action but also with anti-inflammatory effect of LEV [53]. Research carried out by Yan et al., [54] concerning LEV and neurogenesis, indicated a significant impact of LEV on the process of proliferation, migration and differentiation of new-born cells. They found that LEV enhanced cell proliferation and neuroblast differentiation by increasing the expression of antioxidants and PI3K and the level of phosphorylated Akt in the mouse hippocampus. On the other hand, results from studies by the authors of the presented study with using LEV treatment alone and in combination with arachidonyl2'-chloroethylamide (ACEA), indicated, that LEV injected alone decreased significantly the process of neurogenesis, whereas the combination LEV+ACEA+PMSF significantly increased the total number of new-born neurons compare to the control group [55]. Moreover, the authors reported in their previous results that ACEA alone and in combination with another antiepileptic drug valproate significantly increased neurogenesis in healthy and PILO mice [32,38]. Similar results were obtained by Compagnucci and et al. [31], where the endocannabinoid anandamide (AEA) as well as ACEA enhanced NSC differentiation into neurons, whereas the $\mathrm{CB}_{2}$-specific agonist JWH133 was ineffective. Investigations with mouse PILO model of epilepsy allowed the observation and evaluation of the neurogenesis changes in the epileptic mouse brain.

\section{CONCLUSIONS}

From the results obtained in the presented study, it can be conclude that long-term treatment with an antiepileptic drug like LEV leads to a reduction of hippocampal proliferation, migration and differentiation of new-born cells, whereas the use of the combination of ACEA and LEV significantly increased neurogenesis. Unaffected neurogenesis certainly has great importance for patients suffering from epilepsy and 
undergoing long-term treatment with antiepileptic drugs; therefore an assisted antiepileptic therapy with ACEA is worth consideration in further preclinical trials.

\section{Acknowledgments}

The project was supported by 2 grants from the National Science Centre (No.: UMO2012/05/B/NZ7/02459 and UMO2015/19/B/NZ7/03694, Krakow, Poland). Marta Andres-Mach is a Recipient of the Fellowship for Leading Young Researchers from the Ministry of Science and Higher Education in Warsaw, Poland).

\section{REFERENCES}

1.European Medicines Agency: Keppra: EPAR - product information 2014. http://www.ema.europa.eu/docs/en_GB/document_library/ EPAR_-_Product_Information/ human /000277/WC500041334.pdf (access. 12.11.2017).

2.Luszczki JJ, Andres MM, Czuczwar P, Cioczek-Czuczwar A., Ratnaraj N, Patsalos PN, Czuczwar SJ. Pharmacodynamic and pharmacokinetic characterization of interactions between levetiracetam and numerous antiepileptic drugs in the mouse maximal electroshock seizure model: an isobolographic analysis. Epilepsia 2006; 47: 10-20.

3. Luszczki JJ, Andres-Mach MM, Ratnaraj N, Patsalos PN, Czuczwar SJ. Levetiracetam and felbamate interact both pharmacodynamically and pharmacokinetically: an isobolographic analysis in the mouse maximal electroshock model. Epilepsia 2007; 48: 806-815.

4.Dudra-Jastrzebska M, Andres-Mach MM, Ratnaraj N, Patsalos PN, Czuczwar SJ, Luszczki JJ. Isobolographic characterization of the anticonvulsant interaction profiles of levetiracetam in combination with clonazepam, ethosuximide, phenobarbital and valproate in the mouse pentylenetetrazole-induced seizure model. Seizure 2009; 18: 607-614.

5. Dudra-Jastrzebska M, Andres-Mach MM, Sielski M, Ratnaraj N, Patsalos PN, Czuczwar SJ, Luszczki JJ. Pharmacodynamic and pharmacokinetic interaction profiles of levetiracetam in combination with gabapentin, tiagabine and vigabatrin in the mouse pentylenetetrazole-induced seizure model: an isobolographic analysis. Eur J Pharmacol. 2009; 605: 87-94.

6. Barton ME, Klein BD, Wolf $\mathrm{HH}$, White HS. Pharmacological characterization of the $6 \mathrm{~Hz}$ psychomotor seizure model of partial epilepsy. Epilepsy Res. 2001; 47: 217-227.

7. Florek-Luszczki M, Wlaz A, Zagaja M, Andres-Mach M, Kondrat-Wrobel MW, Luszczki JJ. Effects of WIN 55, 212-2 (a synthetic cannabinoid $\mathrm{CB} 1$ and $\mathrm{CB} 2$ receptor agonist) on the anticonvulsant activity of various novel antiepileptic drugs against $6 \mathrm{~Hz}$-induced psychomotor seizures in mice. Pharmacol Biochem Behav. 2015; 30: 53-58.

8. Xu T, Bajjalieh SM. SV2 modulates the size of the readily releasable pool of secretory vesicles. Nat Cell Biol. 2001; 3(8): 691-698.

9.Zou H, Brayer SW, Hurwitz M, Niyonkuru C, Fowler LE, Wagner AK. Neuroprotective, neuroplastic, and neurobehavioral effects of daily treatment with levetiracetam in experimental traumatic brain injury. Neurorehabil Neural Repair. 2013; 27: 878-88.

10. Wang H, Gao J, Lassiter TF, McDonagh DL, Sheng H, Warner DS, Lynch JR., Laskowitz DT. Levetiracetam is neuroprotective in murine models of closed head injury and subarachnoid hemorrhage. Neurocrit Care. 2006; 5: 71-78.

11. Gibbs JE, Cock HR. Administration of levetiracetam after prolonged status epilepticus does not protect from mitochondrial dysfunction in a rodent model. Epilepsy Res. 2007; 73: 208-212.

12. Szaflarski JP, Sangha KS, Lindsell CJ, Shutter LA. Prospective, randomized, single-blinded comparative trial of intravenous levetiracetam versus phenytoin for seizure prophylaxis. Neurocrit Care. 2010; 12: 165-172.

13. Steinbaugh LA, Lindsell CJ, Shutter LA, Szaflarski JP. Initial EEG predicts outcomes in a trial of levetiracetam vs. fosphenytoin for seizure prevention. Epilepsy Behav. 2012; 23: 280-284.

14. Shetty AK. Prospects of levetiracetam as a neuroprotective drug against status epilepticus, traumatic brain injury, and stroke. Front Neurol. 2013; 4: 172 .

15. Plech T, Luszczki JJ, Wujec M, Flieger J, Pizoń M. Synthesis, characterization and preliminary anticonvulsant evaluation of some 4-alkyl-1,2,4-triazoles. Eur J Med Chem. 2013; 60: 208-215.
16. Kamiński K, Zagaja M, Łuszczki JJ, Rapacz A, Andres-Mach M, Latacz G, Kieć-Kononowicz K. Design, synthesis and anticonvulsant activity of new hybrid compounds derived from 2-(2,5-dioxopyrrolidin-1-yl) propanamides and 2-(2,5-dioxopyrroli-din-1-yl) butanamides. J Med Chem. 2015; 58: 5274-5286.

17. Kamiński K, Zagaja M, Rapacz A, Łuszczki JJ, Andres-Mach M, Abram M, Obniska J. New hybrid molecules with anticonvulsant and antinociceptive activity derived from 3-methyl- or 3,3-dimethyl-1[1-oxo-1-(4-phenylpiperazin-1-yl)propan-2-yl]pyrrolidine-2,5-diones. Bioorg Med Chem. 2016; 24: 606-618.

18. Abram M, Zagaja M, Mogilski Sz, Andres-Mach M, Latacz G, Baś S, Łuszczki JJ, Kieć-Kononowicz K, Kamiński K. Multifunctional hybrid compounds derived from 2-(2,5-dioxopyrrolidin-1-yl)-3methoxypropanamides with anticonvulsant and antinociceptive properties. J Med Chem. 2017; 60: 8565-8579.

19. Blair RE, Deshpande LS, Sombati S, Falenski KW, Martin BR, DeLorenzo RJ. Activation of the cannabinoid type-1 receptor mediates the anticonvulsant properties of cannabinoids in the hippocampal neuronal culture models of acquired epilepsy and status epilepticus. J Pharmacol Exp Ther. 2006; 317: 1072-1078.

20. Deshpande LS, Blair RE, Ziobro JM, Sombati S, Martin BR, DeLorenzo RJ Endocannabinoids block status epilepticus in cultured hippocampal neurons. Eur J Pharmacol. 2007; 558: 52-59.

21.Luszczki JJ, Czuczwar P, Cioczek-Czuczwar A, Dudra-Jastrzebska M, Andres-Mach M, Czuczwar SJ. Effect of arachidonyl-2'chloroethylamide, a selective cannabinoid CB1 receptor agonist, on the protective action of the various antiepileptic drugs in the mouse maximal electroshock induced seizure model. Prog Neuropsychopharmacol Biol Psychiatry. 2010; 34: 18- 25.

22. Garcia C, Palomo-Garo C, Garcia-Arencibia M, Ramos J, Pertwee R, Fernandez-Ruiz J. Symptom-relieving and neuroprotective effects of the phytocannabinoid $\triangle$-THCV in animal models of Parkinson's disease. Br J Pharmacol. 2011; 163: 1495-1506

23. Andres-Mach M, Zolkowska D, Barcicka-Klosowska B, Haratym-Maj A, Florek-Luszczki M, Luszczki JJ. Effect of ACEA-a selective cannabinoid $\mathrm{CB} 1$ receptor agonist on the protective action of different antiepileptic drugs in the mouse pentylenetetrazole-induced seizure model. Prog Neuropsychopharmacol Biol Psychiatry. 2012; 39: 301-309.

24. Morena M, Campolongo P. The endocannabinoid system: An emotional buffer in the modulation of memory function. Neurobiol Learn Mem. 2013; 112: 30-43

25. Citraro R, Russo E., Ngomba RT, Nicoletti F, Scicchitano F, Whalley BJ, Calignano A, De Sarro G. CB1 agonists, locally applied to the corticothalamic circuit of rats with genetic absence epilepsy, reduce epileptic manifestations. Epilepsy Res. 2013; 106: 74-82.

26. Kochman LJ, dos Santos AA, Fornal CA, Jacobs BL. Despite strong behavioral disruption, Delta 9-tetrahydrocannabinol does not affect cell proliferation in the adult mouse dentate gyrus. Brain Res. 2006; 1113: 86-93.

27. Wolf SA, Bick-Sander A,Fabel K, Leal-Galicia P, Tauber S, RamirezRodriguez G, Müller A, Melnik A, Waltinger TP, Ullrich O, Kempermann G. Cannabinoid receptor $\mathrm{CB} 1$ mediates baseline and activity-induced survival of new neurons in adult hippocampal neurogenesis. Cell Commun Signal. 2010; 8: 12.

28. Palazuelos J, Ortega Z, Diaz-Alonso J, Guzman M, Galve-Roperh I. CB2 cannabinoid receptors promote neural progenitor cell proliferation via mTORC1 signaling. J Biol Chem. 2012; 287: 1198-1209.

29. Jiang W, Zhang Y, Xiao L, Van Cleemput J, Ji SP, Bai G, Zhang X. Cannabinoids promote embryonic and adult hippocampus neurogenesis and produce anxiolytic- and antidepressant-like effects. J Clin Invest. 2005; 115: 3104-3116.

30. Abboussi O, Tazi A, Paizanis E, El Ganouni S. Chronic exposure to WIN55,212-2 affects more potently spatial learning and memory in adolescents than in adult rats via a negative action on dorsal hippocampal neurogenesis. Pharmacol Biochem Behav. 2014; 120: 95-102.

31. Compagnucci C, Di Siena S, Bustamante MB, Di Giacomo D, Di Tommaso M, Maccarrone M, Grimaldi P, Sette C. Type-1 (CB1) cannabinoid receptor promotes neuronal differentiation and maturation of neural stem cells. PLoS ONE 2013; 8: e54271.

32. Andres-Mach M, Zagaja M, Haratym-Maj A, Rola R, Maj M, Haratym J, Dudra-Jastrzębska M, Łuszczki JJ. A long-term treatment with arachidonyl-2'-chloroethylamide combined with valproate increases neurogenesis in a mouse pilocarpine model of epilepsy. Int J Mol Sci. 2017; 18: 900

33. Luszczki JJ, Czuczwar P, Cioczek-Czuczwar A, Czuczwar SJ. Arachidonyl-2'-chloroethylamide, a highly selective cannabinoid CB1 receptor agonist, enhances the anticonvulsant action of valproate in the 
mouse maximal electroshock-induced seizure model. Eur J Pharmacol. 2006; 547: 65-74.

34. Bhaskaran MD, Smith BN. Cannabinoid-mediated inhibition of recurrent excitatory circuitry in the dentate gyrus in a mouse model of temporal lobe epilepsy. PLoS ONE 2010; 5: e10683.

35. Mazzuferri M, Kumar G, Rospo C, Kaminski RM. Rapid epileptogenesis in the mouse pilocarpine model: Video-EEG, pharmacokinetic and histopathological characterization. Exp Neurol. 2012; 238: 156-167.

36. Racine RJ, Gartner JG, Burnham WM. Epileptiform activity and neural plasticity in limbic structures. Brain Res. 1972; 47: 262-268.

37. Curia G, Longo D, Biagini G, Jones RS, Avoli M. The pilocarpine model of temporal lobe epilepsy. J Neurosci Methods. 2008; 172: 143-157.

38. Andres-Mach M, Haratym-Maj A, Zagaja M, Rola R, Maj M, ChrościńskaKrawczyk M, Luszczki JJ. ACEA (a highly selective cannabinoid CB1 receptor agonist) stimulates hippocampal neurogenesis in mice treated with antiepileptic drugs. Brain Res. 2015; 1624: 86-94.

39. Andres-Mach M, Zolkowska D, Barcicka-Klosowska B, Haratym-Maj A, Florek-Luszczki M, Luszczki JJ. Effect of ACEA - a selective cannabinoid $\mathrm{CB} 1$ receptor agonist on the protective action of different antiepileptic drugs in the mouse pentylenetetrazole-induced seizure model. Prog Neuropsychopharmacol Biol Psychiatry. 2012; 39: 301-309.

40. Vinet J, Vainchtein ID, Spano C, Giordano C, Bordini D, Curia G Dominici M, Boddeke HW, Eggen BJ, Biagini G. Microglia are less pro-inflammatory than myeloid infiltrates in the hippocampus of mice exposed to status epilepticus. Glia 2016; 64: 1350-1362.

41. Abercrombie M. Estimation of nuclear population from microtome sections. Anat Rec. 1946; 94: 239-247.

42. Cortes-Altamirano JL, Olmos-Hernández A, Bonilla-Jaime H, Bandala C, González-Maciel A, Alfaro-Rodríguez A. Levetiracetam as an antiepileptic, neuroprotective, and hyperalgesic drug. Neurol India. 2016; 64(6): 1266-1275.

43. Zou H, Brayer SW, Hurwitz M, Niyonkuru C, Fowler LE, Wagner AK. Neuroprotective, neuroplastic, and neurobehavioral effects of daily treatment with levetiracetam in experimental traumatic brain injury. Neurorehabil Neural Repair. 2013; 27: 878-88.

44. Crepeau AZ, Treiman DM. Levetiracetam: a comprehensive review. Expert Rev Neurother. 2010; 10: 159-171.
45. Micov A, Tomic M, Popovic B, Stepanovic-Petrovic R. Theantihyperalgesic effect of levetiracetam in an inflammatory model ofpain in rats: Mechanism of action. Br J Pharmacol. 2010; 161: 384-392. 46. Stepanovic-Petrovic RM, Micov A, Tomic M, Ugresic ND. The localperipheral antihyperalgesic effect of levetiracetam and its mechanism ofaction in an inflammatory pain model. Anesth Analg. 2012; 115: 1457-1466.

47. Tomic MA, Micov AM, Stepanovic-Petrovic RM. Levetiracetaminteracts synergistically with nonsteroidal analgesics and caffeine toproduce antihyperalgesia in rats. J Pain 2013; 14: 1371-1382.

48. Shannon H, Eberle E, Peters S. Comparison of the effects ofanticonvulsant drugs with diverse mechanisms of action in the formalintest in rats. Neuropharmacology 2005; 48: 1012-1-20.

49. Ozcan M, Ayar A, Canpolat S, Kutlu S. Antinociceptive efficacy oflevetiracetam in a mice model for painful diabetic neuropathy. Acta Anaesthesiol Scand. 2008; 52: 926-930.

50. Falah M, Madsen C, Holbech JV, Sindrup SH. A randomized, placebocontrolledtrial of levetiracetam in central pain in multiple sclerosis. Eur J Pain 2012; 16: 860-869.

51. Rossi S, Mataluni G, Codecà C, Fiore S, Buttari F, Musella A, et al.Effects of levetiracetam on chronic pain in multiple sclerosis: Results of apilot, randomized, placebo-controlled study. Eur J Neurol. 2009; 16: 360-366.

52. Lee DS, Ryu HJ, Kim JE, Choi HC, Kim YI, Song HK, et al. The effectof levetiracetam on status epilepticus-induced neuronal death in the rathippocampus. Seizure 2013; 22: 368-377.

53. Kilicdag H, Daglioglu K, Erdogan S, Guzel A, Sencar L, Polat S,Zorludemir S. The effect of levetiracetam on neuronal apoptosis inneonatal rat model of hypoxic ischemic brain injury. Early Hum Dev. 2013; 89: 355-360.

54. Yan BC, Shen H, Zhang Y, Zhu X, Wang J, Xu P, Jiang D, Yu X. The antiepileptic drug levetiracetam promotes neuroblast differentiation and expression of superoxide dismutase in the mouse hippocampal dentate gyrus via PI3K/Akt signalling. Neurosci Lett. 2018; 662: 84-90. 55.Zagaja M, Haratym-Maj A, Szewczyk A, Rola R, Maj M, Łuszczki JJ, Andres-Mach M. Levetiracetam combined with ACEA, highly selective cannabinoid CB1 receptor agonist changes neurogenesis in adolescent mouse brain. Cell Tissue Res. 2017; (in press). 